\title{
Aberrant NLRP3 inflammasome associated with aryl hydrocarbon receptor potentially contributes to the imbalance of T-helper cells in patients with acute myeloid leukemia
}

\author{
YAN JIA $^{1,2}$, CHEN ZHANG ${ }^{1}$, MINGQIANG HUA ${ }^{1}$, MIN WANG $^{3}$, PING CHEN $^{3}$ and DAOXIN MA ${ }^{1}$ \\ ${ }^{1}$ Department of Hematology, Qilu Hospital, Shandong University, Jinan, Shandong 250012; ${ }^{2}$ Department of Hematology, \\ Jining First People's Hospital, Jining, Shandong 272111; ${ }^{3}$ Department of Hematology, Jinan Central Hospital, \\ Shandong University, Jinan, Shandong 250013, P.R. China
}

Received March 1, 2016; Accepted March 3, 2017

DOI: $10.3892 / \mathrm{ol} .2017 .7177$

\begin{abstract}
Acute myeloid leukemia (AML) is a hematological malignancy in which the immune response serves a pivotal role in progression. Aryl hydrocarbon receptor (AHR) is involved in the modulation of the immune system, particularly in the differentiation of T-helper cell (Th) subsets. Although the NLR family pyrin domain-containing 3 (NLRP3) inflammasome has been implicated as essential in the pathogenesis of autoimmune and inflammatory diseases, the role it serves in the development of AML remains unknown. Therefore, in order to identify and describe the possible roles of AHR, as well as NLRP3 inflammasome, in the pathogenesis of AML and their relationship with Th subsets (Th1 Th22), the present study investigated the mRNA expression levels of AHR and NLRP3 inflammasome molecules in the peripheral blood and bone marrow. Concentrations of plasma IL-18 were also investigated in peripheral blood by ELISA, as well as the proportions of Th22 and Th1. In the present study, there were three groups: Newly diagnosed (ND) patients; complete remission (CR); and normal controls. A markedly increased expression of NLRP3 inflammasome molecules in bone marrow mononuclear cells (BMMCs) from newly diagnosed (ND) patients compared with patients in complete remission (CR) was identified. NLRP3 inflammasome molecules were also observed to be aberrantly expressed in peripheral blood (PB) mononuclear cells (PBMCs), accompanied with aberrant interleukin (IL)-18 levels in PB plasma. The relative level of IL-18 mRNA became normal after the ND patients with AML achieved CR. In bone marrow, the expression of AHR was significantly higher in ND patients than in CR patients. Furthermore, the expression
\end{abstract}

Correspondence to: Dr Daoxin Ma, Department of Hematology, Qilu Hospital, Shandong University, 107 West Wenhua Road, Jinan, Shandong 250012, P.R. China

E-mail: daoxinma@sdu.edu.cn

Key words: inflammasome, NLRP3, T-helper cells, Th1, Th22, cytokine, IL-18 level of NLRP3 inflammasome molecules was significantly correlated with AHR expression in patients with AML. In the Th subsets, a significantly increased proportion of Th22 in PB from ND patients compared with CR patients or controls was identified, accompanied with decreased Th1. It was concluded that the NLRP3 inflammasome, associated with AHR, was involved in the development of AML and may have influenced the differentiation of Th subsets.

\section{Introduction}

Acute myeloid leukemia (AML) is a hematopoietic malignancy characterized by the accumulation of clonal myeloid precursor in the bone marrow (1). Despite improvements in chemotherapy and the development of novel drugs, the prognosis for most AML subtypes remains poor (1). It is well recognized that abnormalities in the immune system are involved in the pathogenesis of AML (2). Previous studies have demonstrated that aberrant T-helper cells (Th) are involved in in AML progress. It has been established that the innate immune response is closely associated with the adaptive immune response; however, research regarding the innate immune response in AML pathogenesis is limited (3).

The activation of the innate immune response requires the recognition of pathogen-associated molecular patterns (PAMPs) or danger-associated molecular patterns (DAMPs) by pattern recognition receptors (PRRs) (4). The nucleotide-binding and oligomerization domain-like receptor (NLR) family are typical PRRs. Inflammasomes are essential for the activation of the innate immune response. In recent decades, the NLR family pyrin domain-containing 3 (NLRP3) inflammasome has attracted attention as it may be activated by both PAMPs and DAMPs (5). The NLRP3 inflammasome includes three main components: The sensor protein, NLRP3, the adaptor protein, apoptosis-associated speck-like protein (ASC), and pro-caspase-1. To activate the NLRP3 inflammasome, there are two steps (5). The first step involves the recognition of PAMPs and DAMPs by NLRP3. Nuclear factor $\kappa \mathrm{B}(\mathrm{NF}-\kappa \mathrm{B})$ is activated, resulting in the increased transcription of inflammasome-associated molecules, including inactive NLRP3, pro-interleukin (IL)-18 and pro-IL-1 $\beta$ (6). The second 
step is the formation of a molecular platform; NLRP3 recruits ASC and interacts with pro-caspase-1 (7). This induces the cleavage of pro-caspase-1 to its active form, caspase-1; in turn, caspase- 1 cleaves pro-IL-1 $\beta$ and pro-IL-18 to their biologically active forms, IL-1 $\beta$ and IL-18. The NLRP3 inflammasome has been demonstrated to be involved in the pathogenesis of numerous diseases, including diabetes, chronic kidney disease and coronary heart disease (7). At present, to the best of our knowledge, no study has focused on the role of the NLRP3 inflammasome in AML.

Accumulating evidence indicates that imbalanced Th subset proportions are involved in the pathogenesis of a number of types of tumor, including hematological malignancies; however, the specific role of Th subsets in tumor pathogenesis is under debate. Th22 is a recently identified cluster of differentiation (CD)4+ Th subset, which only secretes IL-22, and does not secrete IL-17 or interferon (IFN)- $\gamma$. Past research has demonstrated that IL-22 is involved in the pathogenesis of many diseases, including inflammatory autoimmune disease (8-11) and hematological diseases, including myelodysplastic syndrome, immune thrombocytopenia (ITP) and acute lymphoblastic leukemia (12-14). A study by Lucas et al suggested that imbalanced Th22 and Th1 subset proportions serve important roles in the development of AML; however, the mechanism for this remains ambiguous (2).

Goergens et al observed that aryl hydrocarbon receptor (AHR) may be involved in the development of AML (15). It has also been suggested that AHR serves a pivotal role in the regulation of the immune response, particularly in Th subset differentiation (16). It has been previously demonstrated that AHR negatively regulates NLRP3 inflammasome activation by inhibiting the transcription of NLRP3, as summarized in a review by Huai (17).

It has been established that NLRP3 inflammasome and the associated cytokines, IL- $1 \beta$ and -18 , modulate the adaptive immune response via the regulation of Th subset differentiation. Gris et al demonstrated that the production of IFN- $\gamma$ in $\mathrm{NLRP}^{-/}$mice was decreased, suggesting that the NLRP3 inflammasome may be associated with the differentiation of the Th1 subset (18).

The present study aimed to investigate the NLRP3 inflammasome, and the associated cytokines IL-1 $\beta$ and -18 , in the development of AML, identify statistical correlations between the NLRP3 inflammasome and Th subsets in the peripheral blood (PB) and bone marrow (BM) microenvironments, and explore their clinical relevance.

\section{Materials and methods}

Patients and controls. A total of 90 newly-diagnosed (ND) patients with AML (42 females and 48 males; age range, 15-75 years; median age, 49 years) and 79 patients exhibiting complete remission (CR) from AML (31 females and 48 males; age range, 15-75 years; median age, 37 years) were included in the study. AML was diagnosed according to the French-American-British classification system (19) and CR was defined using the Word Health Organization Classification (20). Patients that exhibited hypertension, cardiovascular diseases, infection, connective tissue diseases or autoimmune diseases were excluded from the study. A total of 28 healthy controls were included in the study. Bone marrow mononuclear cells (BMMCs) and peripheral blood mononuclear cells (PBMCs) were isolated from the patients with AML and controls. In CR patients, leukemic cells can only marginally be detected (20). Therefore, BMMCs of ND patients were used to represent leukemic cells, whereas BMMCs of the CR patients or controls were used to represent normal cells. Enrollment in the study was between September 2014 and September 2015 at the Qilu Hospital of Shandong University (Jinan, China). Detailed clinical features of the patients with AML and the control group are described in Table I. The present study received approval from the Medical Ethics Committee of the Qilu Hospital of Shandong University. All the patients provided informed consent prior to inclusion in the study.

Flow cytometric analysis. Intracellular cytokines were detected by flow cytometry to identify the cytokine-producing cells. Briefly, heparinized peripheral whole blood $(100 \mu \mathrm{l})$ with an equal volume of RPMI-1640 medium (Invitrogen; Thermo Fisher Scientific, Inc., Waltham, MA, USA), including $25 \mathrm{ng} / \mathrm{ml}$ of phorbol myristate acetate (PMA), $1 \mu \mathrm{g} / \mathrm{ml}$ of ionomycin and $1.7 \mu \mathrm{g} / \mathrm{ml}$ monensin (Alexis Biochemicals, San Diego, CA, USA), was incubated for $4 \mathrm{~h}$ at $37^{\circ} \mathrm{C}$ with $5 \% \mathrm{CO}_{2}$. PMA and ionomycin are $\mathrm{T}$ cell-activating pharmaceuticals that mimic signals generated by the T-cell receptor complex and may stimulate T cells of any antigen specificity. Monensin was used to block intracellular transport mechanisms and led to an accumulation of cytokines in the cells.

All antibodies were purchased from eBioscience, Inc. (San Diego, CA, USA). After incubation, $100 \mu \mathrm{l}$ incubated blood was placed in each tube, the cells were stained with PE-Cy5-conjugated anti-CD3 monoclonal antibody (\#300420) and anti-CD8 monoclonal antibody (\#344714) (both from BioLegend, Inc., San Diego, CA, USA) at room temperature in the dark for $20 \mathrm{~min}$. Then, $100 \mu \mathrm{l}$ reagent A (Fixation) was placed in each tube and incubated at room temperature in the dark for $15 \mathrm{~min}$. Following this, $3 \mathrm{ml}$ PBS was placed in each tube and centrifugated at $1,000 \mathrm{xg}$ for $5 \mathrm{~min}$ at $25^{\circ} \mathrm{C}$, to wash the cells. A total of $100 \mu \mathrm{l}$ reagent $\mathrm{B}$ (Permeabilisation) was put in each tube with FITC-conjugated anti-IFN- $\gamma$ (cat no. 502506), PE-anti-human IL-17A (cat no. 512306) (both from BioLegend, Inc.) and APC-conjugated anti-IL-22 monoclonal antibodies (cat no. 50-7229-42; eBioscience, Inc.) in a total of $100 \mu \mathrm{l}$ buffe. Fixation and permeabilisation reagents were purchased from Caltag; Invitrogen; Thermo Fisher Scientific, Inc., and used according to the manufacturer's protocol. The cells were then stained at room temperature in the dark for $20 \mathrm{~min}$. Subsequent to this, $500 \mu \mathrm{l} \mathrm{PBS}$ was placed in each tube and centrifugated at $1,000 \mathrm{x} \mathrm{g}$ for $5 \mathrm{~min}$ at $25^{\circ} \mathrm{C}$, to wash the cells again.

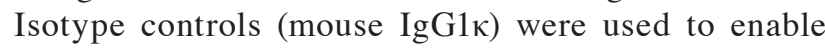
the correct compensation and confirm antibody specificity. Stained cells were analyzed by flow cytometric analysis using a Beckman gallios cytometer (Beckman Coulter, Brea, CA, USA). For analysis, CD3+CD8- lymphocytes were gated, then the proportion of Th22 (CD3+CD8-IL-17-IFNr-IL-22+) and Th1 $(\mathrm{CD} 3+\mathrm{CD} 8-\mathrm{IFN}-\gamma+)$ cells in CD3+CD8- lymphocytes was analyzed.

ELISA of IL-18. BM and PB plasma were collected from ND and $\mathrm{CR}$ patients with AML and normal controls and stored at 
Table I. Clinical characteristics of patients with AML and controls.

\begin{tabular}{|c|c|c|c|}
\hline Characteristics & ND & $\mathrm{CR}$ & Controls \\
\hline Total & 90 & 79 & 28 \\
\hline Age range, years & $14-75$ & $14-75$ & $20-60$ \\
\hline Gender, female/male & $42 / 48$ & $31 / 48$ & $13 / 15$ \\
\hline \multicolumn{4}{|l|}{ Serum levels, g/l } \\
\hline Albumin & $38.11 \pm 5.32$ & $43.30 \pm 4.26$ & - \\
\hline Globulin & $26.00 \pm 4.90$ & $26.76 \pm 4.59$ & - \\
\hline Total protein & $64.11 \pm 6.32$ & $70.11 \pm 5.99$ & - \\
\hline \multicolumn{4}{|l|}{ Cell counts } \\
\hline White blood cells, median, range; $\times 10^{12} / 1$ & $17.11,0.4-218.2$ & $4.98,1.9-14.7$ & $5.10,4.13-10.0$ \\
\hline Red blood cells, median, range; $\mathrm{x} 10^{12} / 1$ & $2.50,1.26-4.55$ & $3.73,2.06-5.13$ & $3.50,3.20-5.5$ \\
\hline Platelets, median, range; $\times 10^{9} / 1$ & $35,4-492$ & $269,49-731$ & $307,105-410$ \\
\hline Lactate dehydrogenase, median, range; U/1 & $492,152-2,906$ & $182,98-459$ & - \\
\hline \multicolumn{4}{|l|}{ French-American-British classification subtype } \\
\hline M1 & 1 & 1 & N/A \\
\hline M2 & 5 & 4 & N/A \\
\hline M3 & 20 & 27 & N/A \\
\hline M4 & 12 & 8 & N/A \\
\hline M5 & 47 & 38 & $\mathrm{~N} / \mathrm{A}$ \\
\hline M6 & 5 & 1 & $\mathrm{~N} / \mathrm{A}$ \\
\hline
\end{tabular}

AML, acute myeloid leukaemia; ND, newly diagnosed patients; CR, complete remission patients.

Table II. Primer sequences.

\begin{tabular}{lll}
\hline Gene & \multicolumn{1}{c}{ Forward, 5'-3' } & \multicolumn{1}{c}{ Reverse, $5^{\prime}-3^{\prime}$} \\
\hline AHR & CAAATCCTTCCAAGCGGCATA & CGCTGAGCCTAAGAACTGAAAG \\
NLRP3 & CAGACTTCTGTGTGTGGGACTGA & TCCTGACAACATGCTGATGTGA \\
ASC & TGGATGCTCTGTACGGGAAG & CCAGGCTGGTGTGAAACTGAA \\
CASP-1 & AAATCTCACTGCTTCGGACATG & GGAACTTGCTGTCAGAGGTCTT \\
IL-18 & GCTTGAATCTAAATTATCAGTC & GAAGATTCAAATTGCATCTTAT \\
\hline
\end{tabular}

AHR, aryl hydrocarbon receptor; NLRP3, nucleotide-binding and oligomersization domain-like receptor family pyrin domain-containing 3; ASC, apoptosis-associated speck-like protein; CASP-1, caspase 1; IL, interleukin.

$-80^{\circ} \mathrm{C}$ immediately after centrifugation $(1,000 \mathrm{x}$ for $5 \mathrm{~min}$ at $\left.25^{\circ} \mathrm{C}\right)$. The plasma was used for the detection of NLRP3-related cytokines. The level of IL-18 in each group was determined using the ELISA method, according to the manufacturer's protocol (lower detection limit $78 \mathrm{pg} / \mathrm{ml}$; eBioscience, Inc.).

Reverse transcription-quantitative polymerase chain reaction (RT-qPCR) analysis. Total RNA was extracted with TRIzol (Invitrogen; Thermo Fisher Scientific, Inc.) according to the manufacturer's protocol. Total RNA $(\sim 1 \mu \mathrm{g})$ from each sample was used to synthesize complementary (c)DNA with the PrimeScript RT reagent kit (Takara Biotechnology Co., Ltd., Dalian, China). The RT reaction was performed at $37^{\circ} \mathrm{C}$ for $15 \mathrm{~min}$, followed by $85^{\circ} \mathrm{C}$ for $5 \mathrm{sec}$. Quantitative PCR was conducted using an LC480II Real-Time PCR system (Roche
Diagnostics, Basel, Switzerland) in accordance with the manufacturer's protocol. For amplification, an initial denaturation step at $95^{\circ} \mathrm{C}$ for $5 \mathrm{~min}$ was followed by 40 cycles at $95^{\circ} \mathrm{C}$ for $15 \mathrm{sec}, 60^{\circ} \mathrm{C}$ for $15 \mathrm{sec}$ and $72^{\circ} \mathrm{C}$ for $40 \mathrm{sec}$. The qPCR reaction contained, in a final volume of $10 \mu \mathrm{l}, 5 \mu \mathrm{l}$ of $2 \mathrm{X}$ SYBR-Green Real-Time PCR Master Mix (Toyobo Co., Ltd., Osaka, Japan), $1 \mu \mathrm{l}$ of cDNA, $3.2 \mu \mathrm{l}$ of $\mathrm{ddH}_{2} \mathrm{O}$, and $0.4 \mu \mathrm{l}$ of the forward and reverse primers. The sequences for all primers are described in Table II. All experiments were conducted in triplicate. The PCR products were analyzed by melt curve analysis and agarose gel electrophoresis to determine product size and to confirm that no by-products were formed. The results were expressed relative to the number of $\beta$-actin transcripts, an internal control. Relative gene expression level was calculated using the $2^{-\Delta \Delta \mathrm{Cq}}$ method (21). 
A

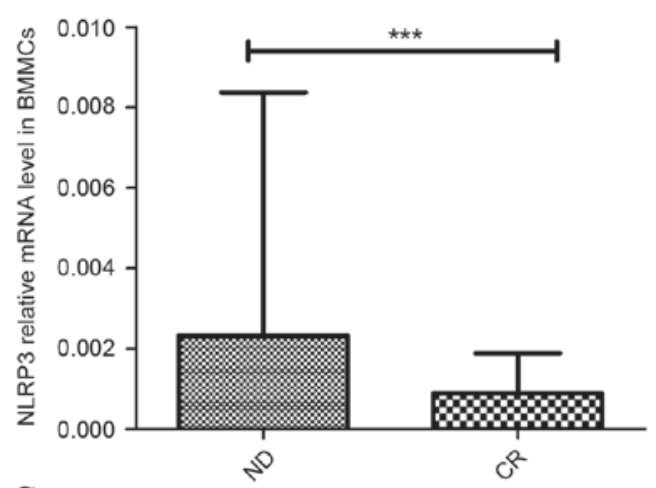

C

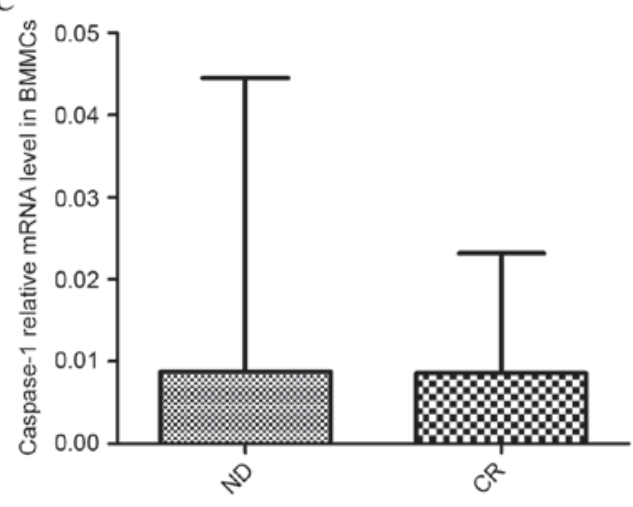

$\mathbf{E}$

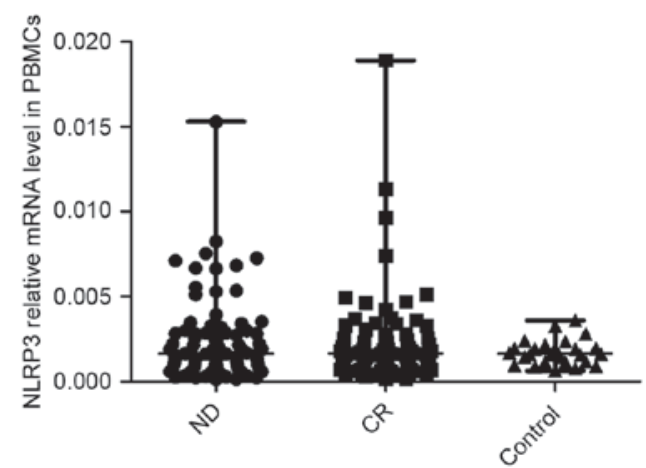

B

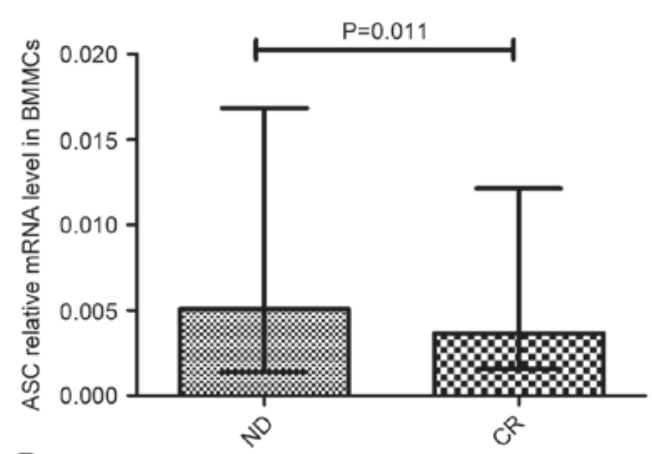

D

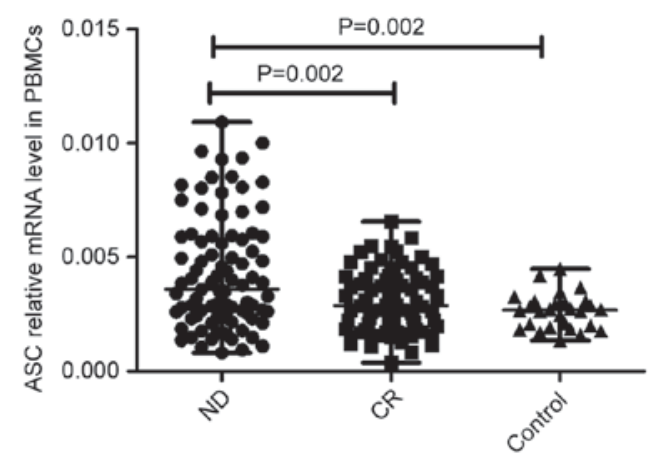

F

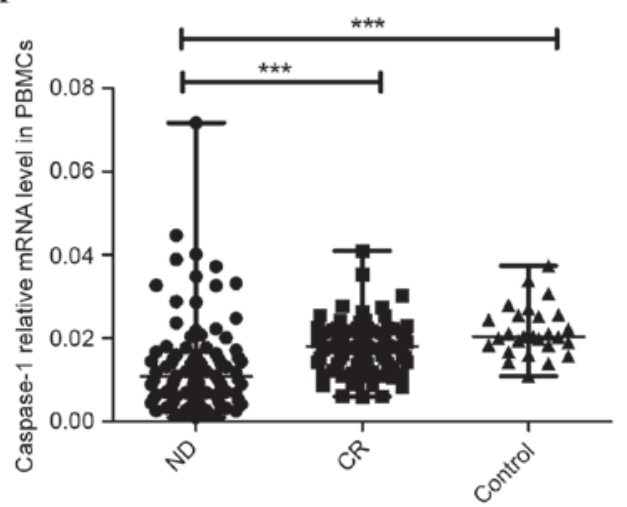

Figure 1. Relative NLRP3 inflammasome molecule (NLRP3, ASC, caspase-1) mRNA expression. A significantly increased expression level of (A) NLRP3, (B) ASC and (C) caspase-1 mRNA in BMMCs was observed in ND patients compared with CR Patients with AML. (D) In PBMCs, the expression of ASC in the ND group was elevated compared with the CR and control groups. (E) No significant difference in NLRP3 expression between ND patients, CR patients and normal controls was identified in PBMCs. (F) The expression of caspase-1 in ND patients was markedly decreased relative to the CR and control groups in PBMCs. ${ }^{* * *} \mathrm{P}<0.001$. NLRP3, NLR family pyrin domain-containing 3; ASC, apoptosis-associated speck-like protein; BMMCs, bone marrow mononuclear cells; ND, newly-diagnosed; CR, complete remission; AML, acute myeloid leukemia; PBMCs, peripheral blood mononuclear cells.

Statistical analysis. Results were expressed as the mean \pm standard deviation, or median (range). The statistical significance of differences in Th cells (including Th1 as well as Th22 in PB) and IL-18 (levels in PB plasma) were determined by ANOVA. The differences in the levels of NLRP3 inflammasome molecules (NLRP3, ASC, caspase-1, IL-18 and IL-1 $\beta$ ) and the transcription factor AHR were determined using the Kruskal-Wallis Test. The differences between two groups were determined by the Mann-Whitney U test, unless data were normally distributed, in which case a T-test was used. The Pearson or Spearman correlation test was used for correlation analysis, depending on the data distribution. All tests were performed with SPSS 13.0 software (SPSS, Inc., Chicago, IL,
USA). $\mathrm{P}<0.05$ was considered to indicate a statistically significant difference.

\section{Results}

NLRP3 inflammasome molecules were aberrantly expressed in patients with AML. NLRP3 inflammasome is a multiprotein complex, which includes NLRP3, ASC and caspase-1. The expression of these proteins was detected in BMMCs and PBMCs with RT-qPCR. In the BM microenvironment, the expression of NLRP3 was significantly higher in the ND AML group (median, 0.0023; range, 0.00029-0.0084) than in the CR AML group (median, 0.00088; range, 0.00049-0.0019; 

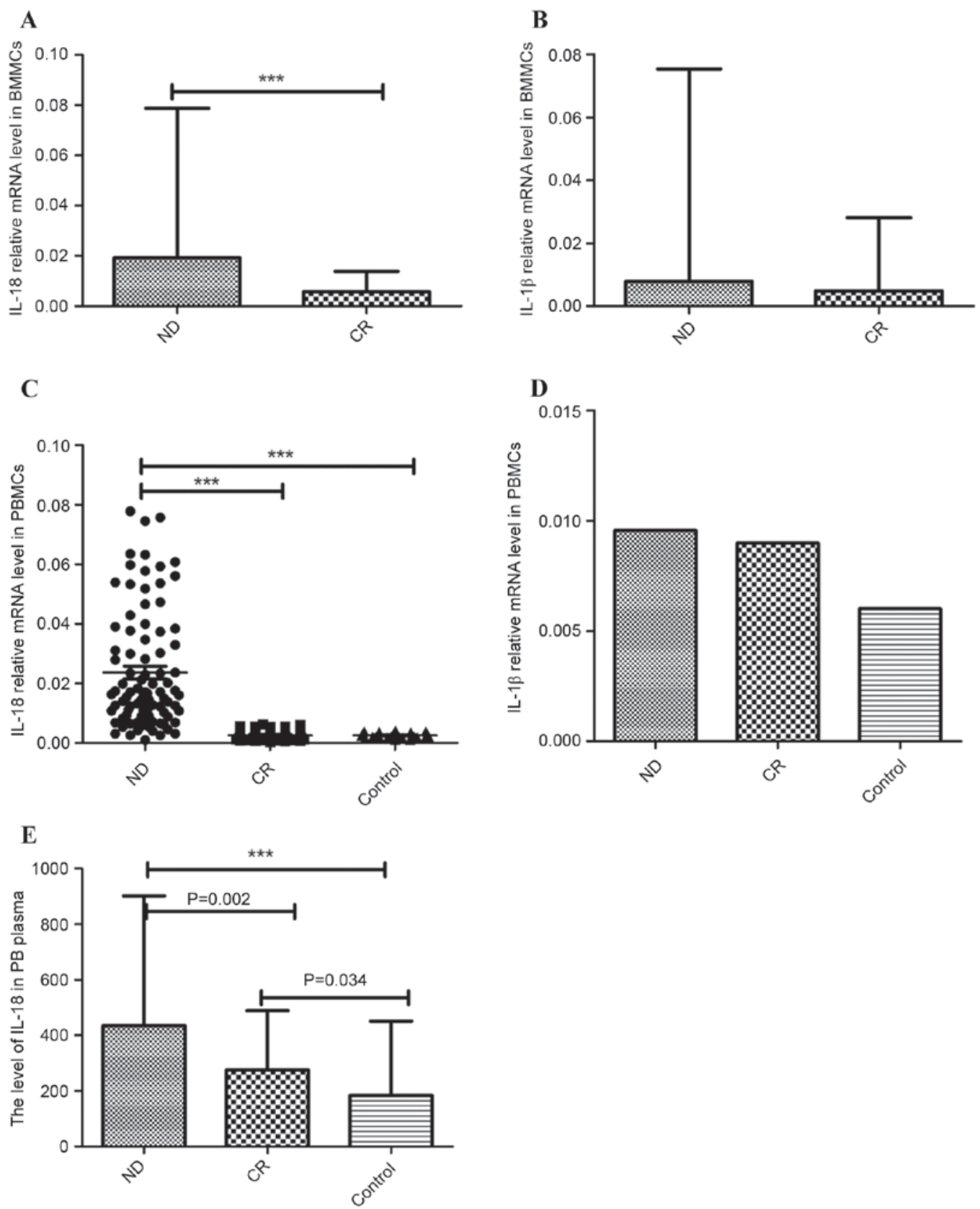

Figure 2. Relative NLRP3 inflammasome-associated molecule (IL-18 and IL-1 $\beta$ ) mRNA and protein level. (A) The IL-18 mRNA level in BMMCs was significantly higher in the ND group than in the CR group. (B) IL-1 13 mRNA levels were elevated in ND patients compared with CR patients in BMMCs; however, no statistical significance was identified. (C) IL-18 mRNA level in PBMCs was significantly higher in the ND group than in the CR and control groups. (D) IL-1 $\beta$ mRNA was increased in the ND and CR groups compared with normal controls in PBMCs; however, no statistical significance was identified. (E) The level of IL-18 in PB plasma was markedly increased in ND patients compared with CR patients and controls. ${ }^{* * *}$ P $<0.001$. NLRP3, NLR family pyrin domain-containing 3; IL, interleukin; BMMCs, bone marrow mononuclear cells; ND, newly diagnosed; CR, complete remission; PBMCs, peripheral blood mononuclear cells; PB, peripheral blood.

$\mathrm{P}<0.001$; Fig. 1A). The data revealed that the expression of ASC was elevated in the ND group (median 0.0051, range 0.0014-0.017) compared with the CR group (median, 0.0037; range, 0.0015-0.012; $\mathrm{P}=0.011$; Fig. 1B). No statistical significance was found between the expression of caspase-1 in the ND group (median, 0.0088; range, 0.00089-0.045) and the CR group (median, 0.0085; range, 0.0049-0.023; $\mathrm{P}=0.457$; Fig. $1 \mathrm{C}$ ).

In the PB microenvironment, the expression of ASC was elevated in the ND group (median 0.0037, range 0.00081-0.026) compared with the CR group (median 0.0029, range $0.00039-0.0066 ; \mathrm{P}=0.002$ ) or the normal control group (median 0.0027, range 0.0014-0.0045; P=0.002) (Fig. 1D), consistent with the results from BMMCs. There was no significant difference of NLRP3 expression between ND patients (median 0.0016, range 0.00014-0.015), CR patients (median 0.0017 , range $0.00018-0.019$ ) and the control group (median 0.0017, range 0.00064-0.0036; Fig. 1E). However, caspase-1 level in ND patients (median 0.011, range 0.00098-0.072) was decreased relative to the $\mathrm{CR}$ group (median 0.018 , range 0.0060-0.041; $\mathrm{P}<0.001$ ) and control group (median 0.020, range 0.011-0.037; $\mathrm{P}<0.001)$ (Fig. 1F). 

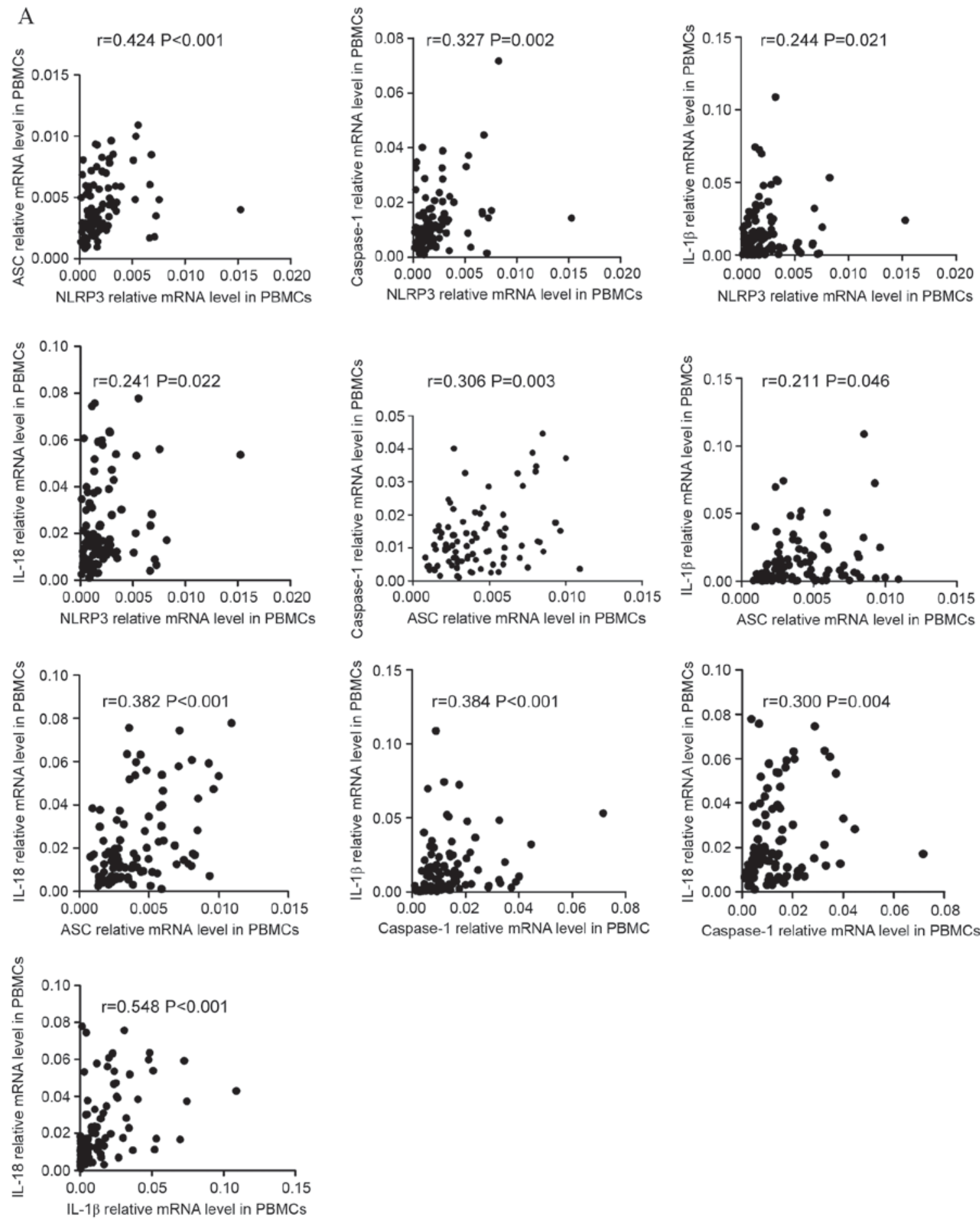

Figure 3. Correlation between the mRNA expression of NLRP3 molecules and cytokines. (A) The mRNA expression of NLRP3 inflammasome molecules in PBMCs and effector cytokines in PBBCs were positively correlated in ND patients. Additionally, PBBC IL- $1 \beta$ mRNA levels demonstrated a positive correlation with IL-18. NLRP3, NLR family pyrin domain-containing 3; PBMCs, peripheral blood mononuclear cells; ND, newly diagnosed; IL, interleukin; CR, complete remission; ASC, apoptosis-associated speck-like protein; BMMCs, bone marrow mononuclear cells.

NLRP3 effector cytokines (IL-1 $\beta$ and IL-18) were abnormal in patients with $A M L$. IL-1 $\beta$ and IL-18 are the main effector cytokines of the NLRP3 inflammasome. In the BM microenvironment of patients with AML, IL-18 mRNA expression was significantly increased in the ND group (median 0.019 , range 0.0034-0.079) relative to the CR group (median 0.0058, range 0.00038-0.014; P<0.001; Fig. 2A). IL-1 $\beta$ mRNA level was also marginally elevated in the ND patients (median 0.0079, range 0.00018-0.075) compared with the $\mathrm{CR}$ patients (median 0.0049, range 0.00090-0.028; $\mathrm{P}=0.116$; Fig. 2B).

In $\mathrm{PB}$, the relative mRNA level of IL-18 in the ND group (median 0.017, range 0.00104-0.078) was significantly higher than in the CR group (median 0.0022, range 0.00030-0.0063; $\mathrm{P}<0.001$ ) and controls (median 0.0023, range 0.00113-0.0042; $\mathrm{P}<0.001$; Fig. 2C). IL-1 $\beta$ mRNA expression was increased in the ND group (median 0.0095, range 0.00012-0.11) and CR 
B
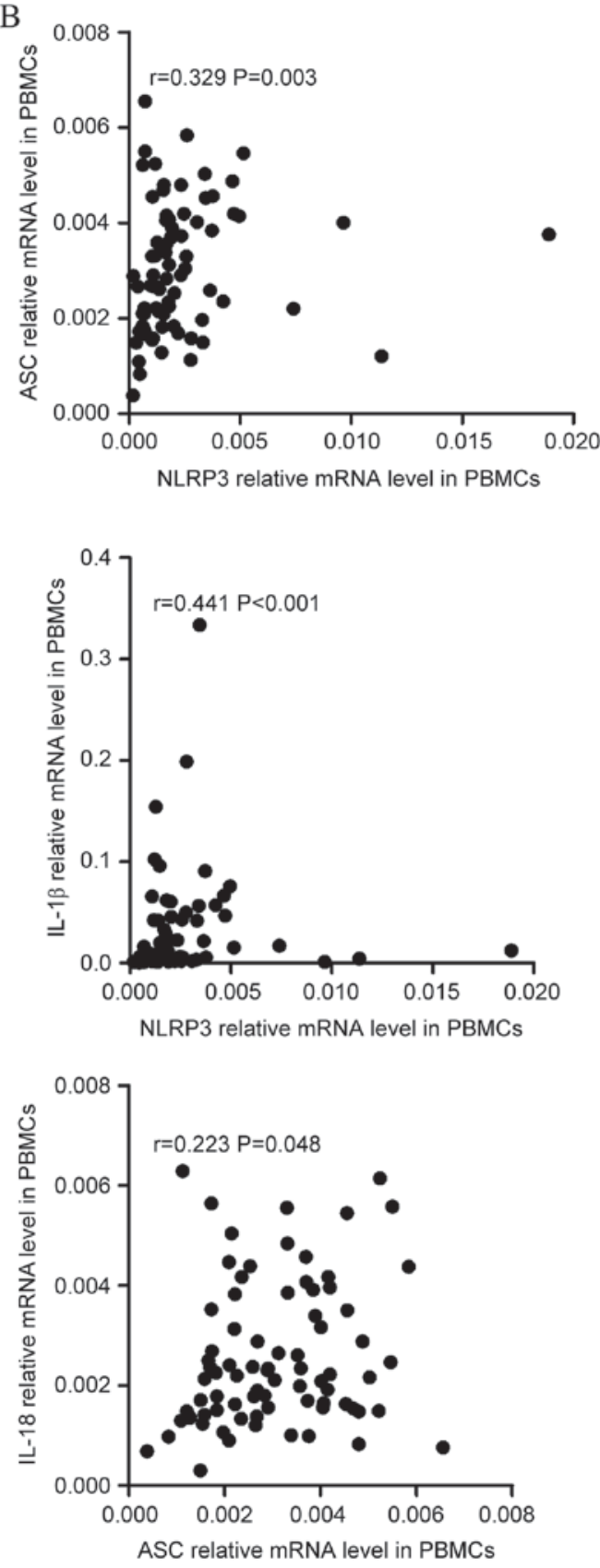
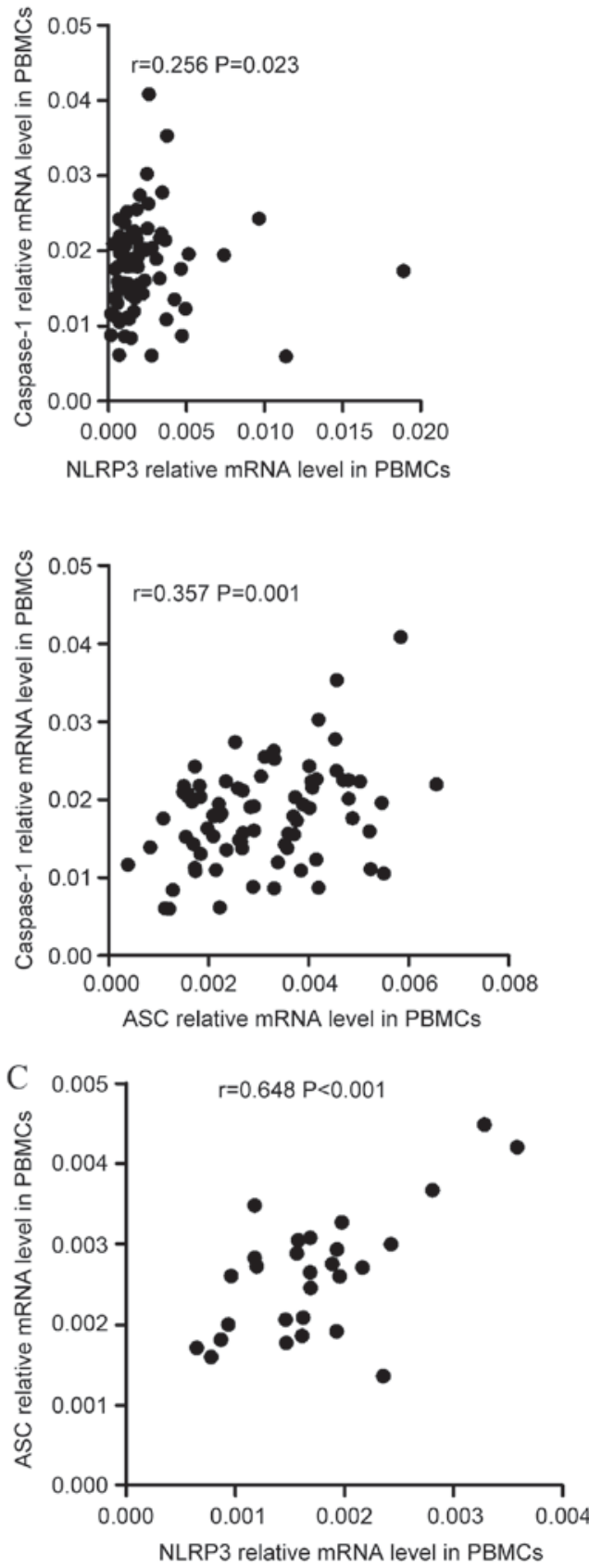

Figure 3. Continued. Correlation between the mRNA expression of NLRP3 molecules and cytokines. (B) In the PBMCs of CR patients, the NLRP3 mRNA level was positively correlated with ASC and IL-1 $\beta$ mRNA level. The relative level of ASC mRNA was positively correlated with caspase-1 and IL-18 mRNA levels. (C) In the PBMCs of controls, a positive correlation between NLRP3 and ASC relative mRNA expression was identified. NLRP3, NLR family pyrin domain-containing 3; PBMCs, peripheral blood mononuclear cells; ND, newly diagnosed; IL, interleukin; CR, complete remission; ASC, apoptosis-associated speck-like protein; BMMCs, bone marrow mononuclear cells.

group (median 0.0090, range 0.00051-0.33) compared with the control group (median 0.0060, range 0.0009-0.011), although no statistical significance was identified (Fig. 2D). No significant difference in IL-1 $\beta$ level was found between the ND and CR groups.

ELISA was used to detect the level of IL-18 protein level in PB plasma. IL-18 was identified as significantly increased in ND patients $(444.717 \pm 219.420 \mathrm{pg} / \mathrm{ml})$ compared with the CR patients $(272.284 \pm 81.776 \mathrm{pg} / \mathrm{ml} ; \mathrm{P}=0.002)$ and controls $(207.296 \pm 98.827$ $\mathrm{pg} / \mathrm{ml}$; $\mathrm{P}<0.001)$. IL-18 serum protein in $\mathrm{CR}$ patients was also increased relative to the control group $(\mathrm{P}=0.034$; Fig. $2 \mathrm{E})$.
Relationships between NLRP3 inflammasome molecules and effector cytokines. To improve the understanding of the NLRP3 inflammasome, correlations between the relative expression level of NLRP3 inflammasome molecules and effector cytokines were investigated. The resulting data indicated that, in PBMCs, the expression levels of NLRP3 inflammasome molecules and effector cytokines were positively correlated in ND patients (Fig. 3A). NLRP3 level was positively correlated with ASC $(r=0.424, \mathrm{P}<0.001)$, caspase-1 $(\mathrm{r}=0.327$, $\mathrm{P}=0.002)$, IL-1 $\beta(\mathrm{r}=0.244, \mathrm{P}=0.021)$, and IL-18 $(\mathrm{r}=0.241$, $\mathrm{P}=0.022$ ) level. ASC level was positively correlated with 
$\mathrm{D}$
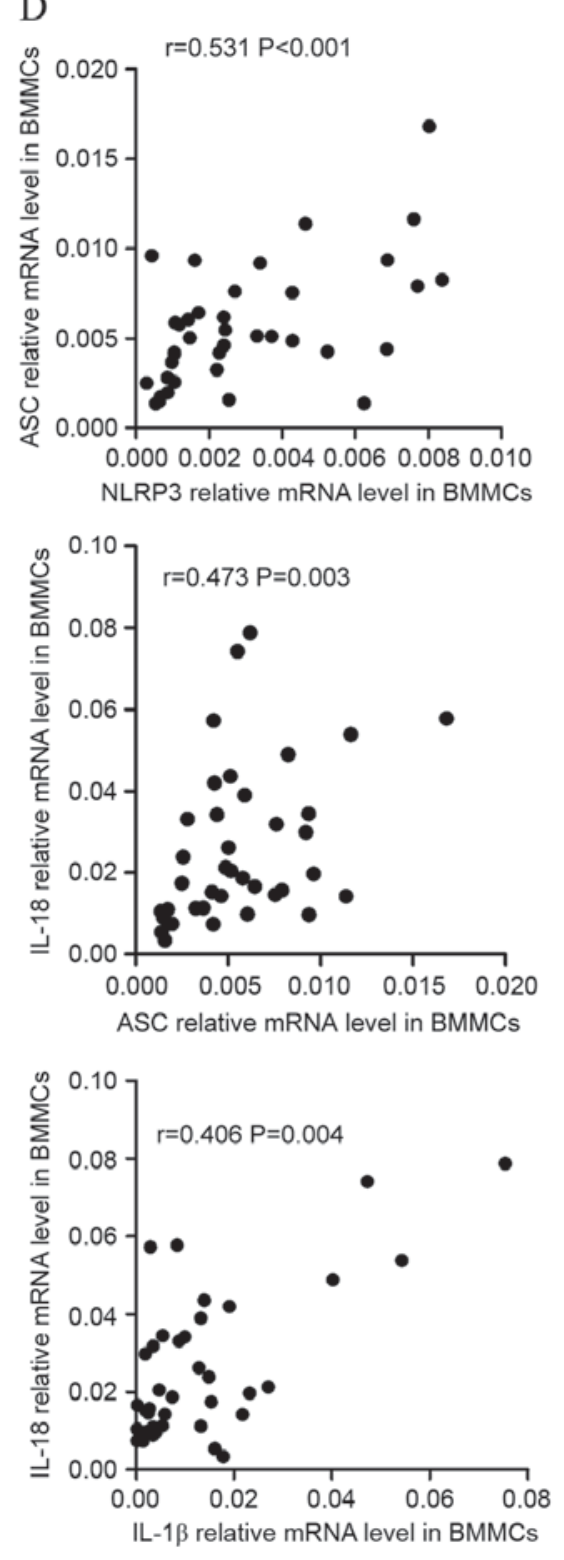
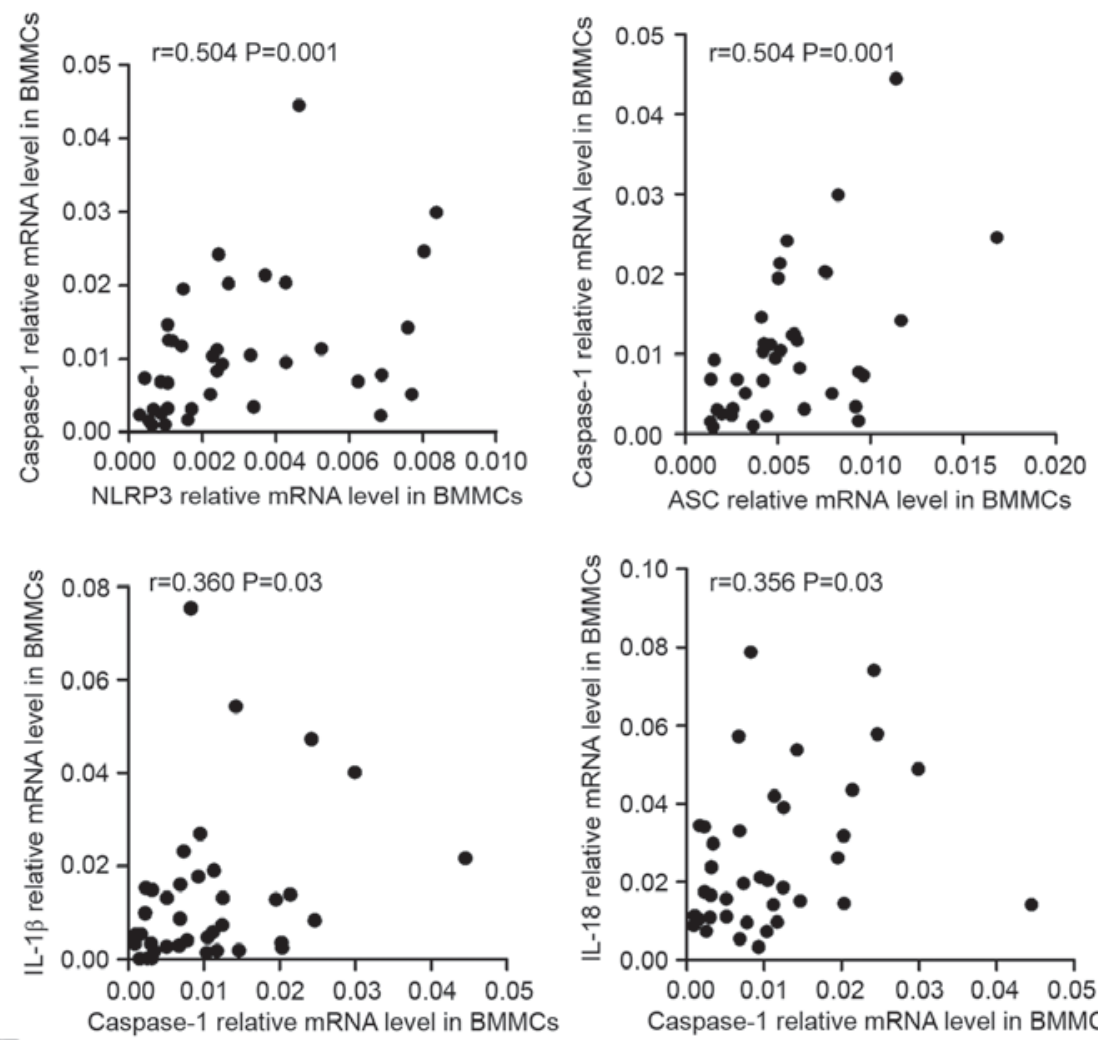

E
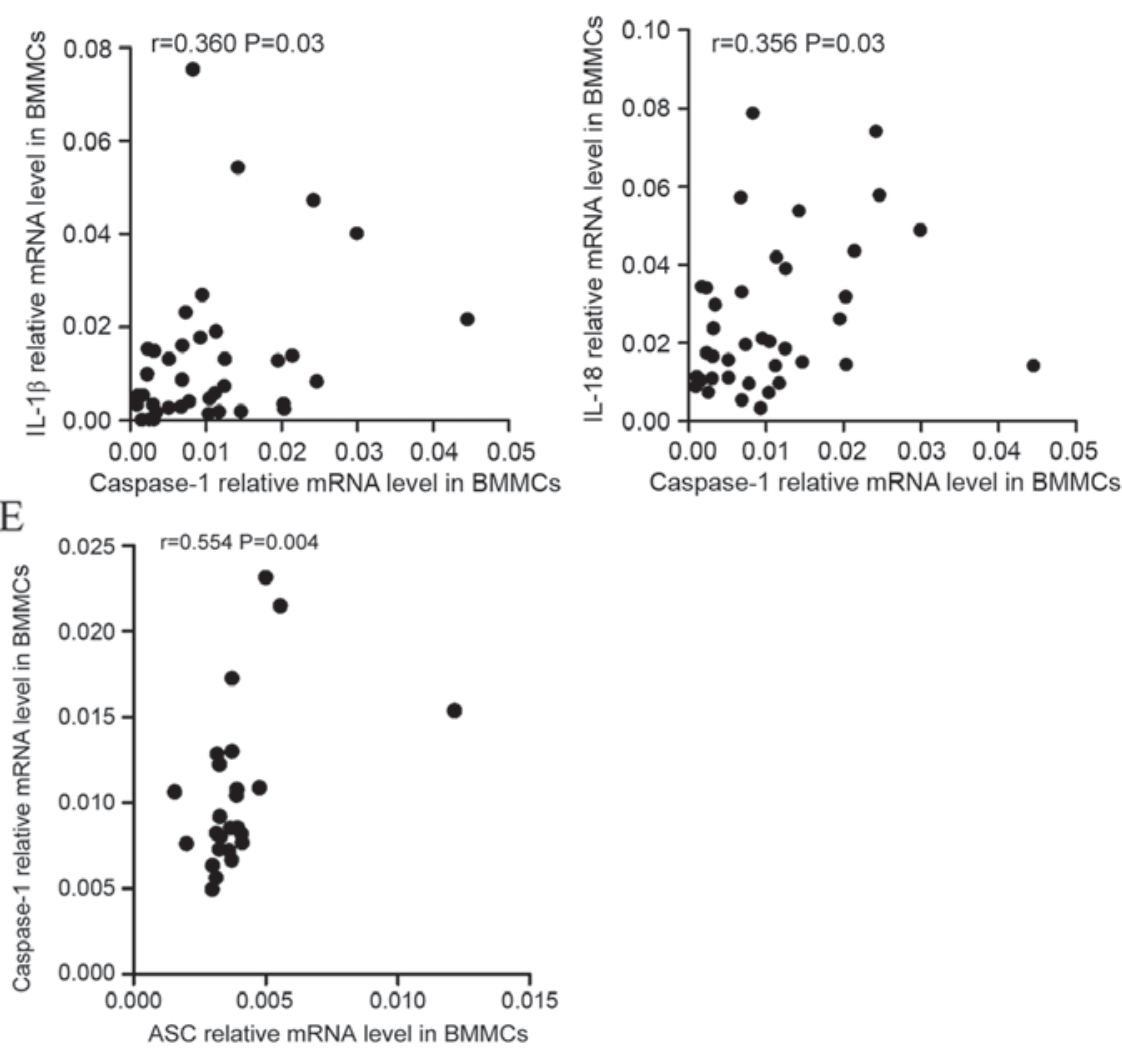

Figure 3. Continued. Correlation between the mRNA expression of NLRP3 molecules and cytokines. (D) In BMMCs of ND patients it was identified that NLRP3 expression level was positively correlated with ASC and caspase-1, and that ASC expression was positively correlated with the caspase-1 mRNA level. IL-18 mRNA in BMMCs was positively correlated with the relative ASC mRNA level. IL-1 $\beta$ and IL-18 mRNA levels were positively correlated with the caspase-1 mRNA level. The IL-1 $\beta$ level was also positively correlated with the level of IL-18 mRNA. (E) In the BMMCs of CR patients, the only significant positive correlation to be identified was between ASC and caspase-1 mRNA levels. NLRP3, NLR family pyrin domain-containing 3; PBMCs, peripheral blood mononuclear cells; ND, newly diagnosed; IL, interleukin; CR, complete remission; ASC, apoptosis-associated speck-like protein; BMMCs, bone marrow mononuclear cells.

caspase-1 $(\mathrm{r}=0.306, \mathrm{P}=0.003), \mathrm{IL}-1 \beta(\mathrm{r}=0.211, \mathrm{P}=0.046)$, and IL-18 ( $\mathrm{r}=0.382, \mathrm{P}<0.001)$ level. Caspase-1 level was positively correlated with IL-1 $\beta(\mathrm{r}=0.384, \mathrm{P}<0.001)$ and IL-18 $(\mathrm{r}=0.300$, $\mathrm{P}=0.004)$ level. As for effector cytokines, IL-1 $\beta$ level showed positive correlation with IL-18 level $(r=0.548, \mathrm{P}<0.001)$. The correlations between the level of NLRP3 inflammasome molecules and effector cytokines in CR patients varied from in ND patients (Fig. 3B). The level of NLRP3 was positively correlated with ASC $(r=0.329, P=0.003)$, caspase-1 $(r=0.256$ $\mathrm{P}=0.023) \mathrm{IL}-1 \beta(\mathrm{r}=0.441, \mathrm{P}<0.001)$ levels. The level of ASC was positively correlated with caspase-1 $(\mathrm{r}=0.357, \mathrm{P}=0.001)$ and IL-18 ( $\mathrm{r}=0.223, \mathrm{P}=0.048)$ levels. No statistically significant correlation was identified between other molecules. In the controls (Fig. 3C), the only positive correlation identified was between NLRP3 and ASC ( $\mathrm{r}=0.648, \mathrm{P}<0.001)$ expression level.

In BMMCs, it was identified that the expression level of NLRP3 molecules were positively correlated with each other. In ND patients, the level of NLRP3 was identified as positively correlated with ASC $(\mathrm{r}=0.531, \mathrm{P}<0.001)$ and caspase-1 $(\mathrm{r}=0.504, \mathrm{P}=0.001)$ level, and ASC level was positively correlated with caspase-1 level ( $\mathrm{r}=0.504, \mathrm{P}=0.001$; Fig. 3D). As for correlations between NLRP3 molecules and effector cytokines, the level of IL-18 was positively correlated with ASC level $(r=0.473, P=0.003)$. IL-1 $\beta$ and $\mathrm{Il}-18$ levels were positively correlated with caspase -1 level $(\mathrm{r}=0.360, \mathrm{P}=0.03$; $\mathrm{r}=0.356, \mathrm{P}=0.03$, respectively). IL-1 $\beta$ level was also identified 
A
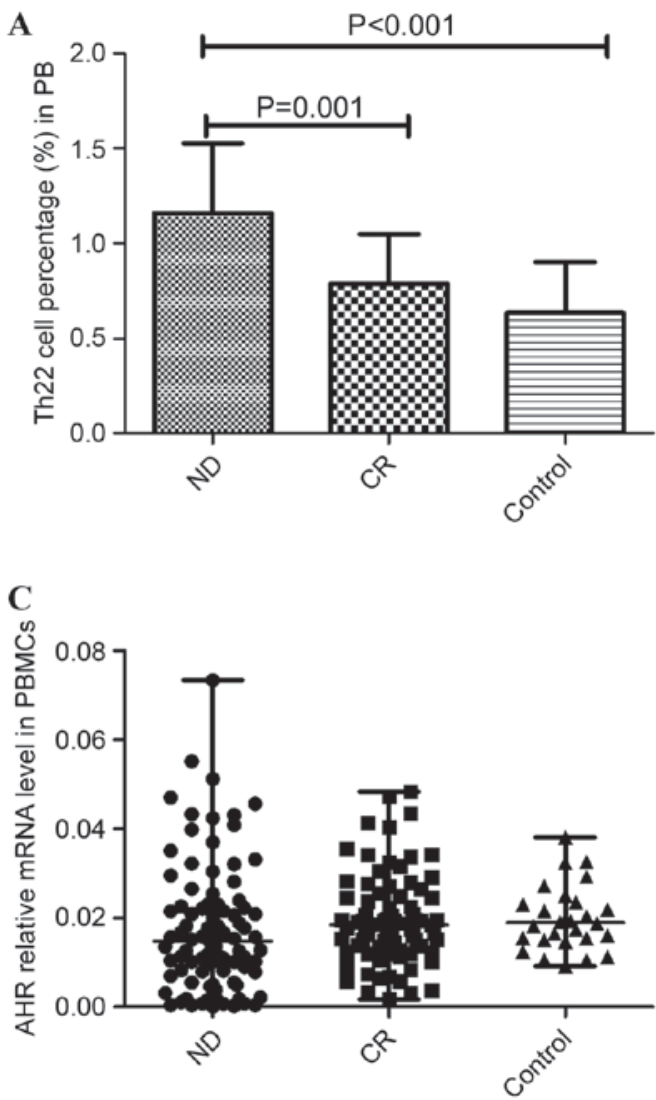

B
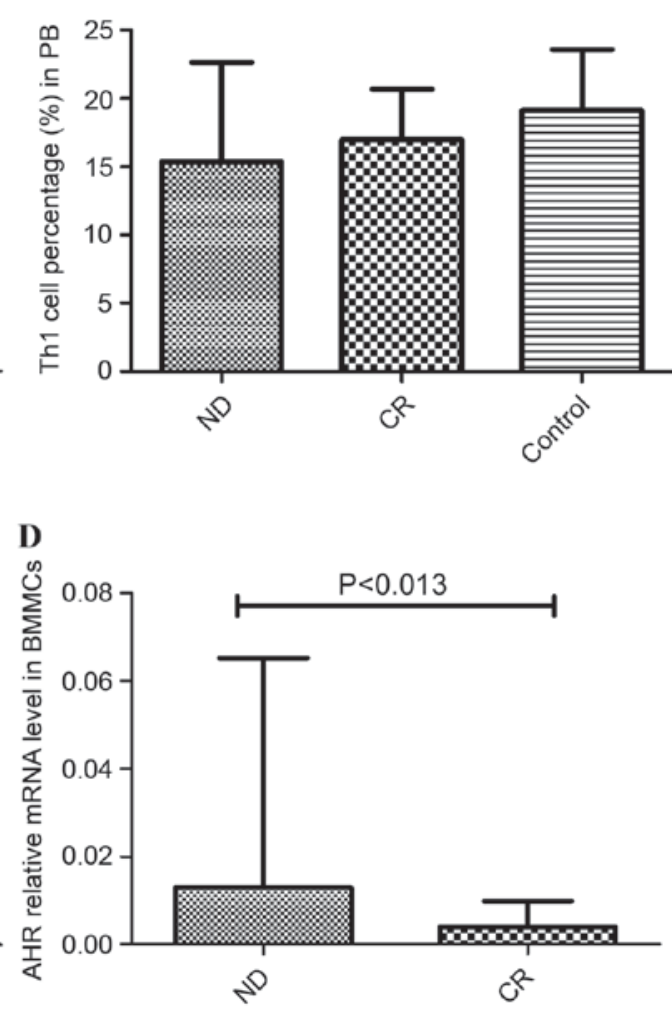

Figure 4. Relative Th subset proportion and expression level of the Th-associated molecule AHR. (A) The frequency of Th22 was increased in ND patients relative to CR patients and normal controls. (B) The relative proportion of the Th1 subset was decreased in ND patients compared with the CR group and controls; however, no statistical significance was identified. (C) No significant difference in relative AHR expression in PBMCs was identified between the ND, CR and control groups. (D) In BMMCs, AHR was markedly increased in the ND group compared to the CR group. Th, T-helper cells; AHR, aryl hydrocarbon receptor; ND, newly diagnosed; CR, complete remission; PBMCs, peripheral blood mononuclear cells; BMMCs, bone marrow mononuclear cells.

to be positively correlated with IL-18 level ( $\mathrm{r}=0.460, \mathrm{P}=0.004)$. In CR patients (Fig. 3E) the only positive correlation identified was between ASC and caspase-1 expression levels ( $r=0.554$, $\mathrm{P}=0.004)$.

Imbalanced Th cells in patients with AML. The results of the present study demonstrated immune deregulation in the PB of patients with AML. The frequency of Th22 was increased in ND patients $(1.16 \pm 0.37 \%)$ relative to $\mathrm{CR}$ patients $(0.79 \pm 0.26 \% ; \mathrm{P}=0.001)$ and controls $(0.635 \pm 0.27 \%$; $\mathrm{P}<0.001$; Fig. 4A). Although the proportion of Th1 cells was reduced in ND patients $(15.38 \pm 7.259 \%)$ compared with the CR group (16.98 $\pm 3.69 \%)$ and controls (19.12 $\pm 4.48 \%$; Fig. 4B), no statistical significance was identified.

Imbalanced AHR in patients with AML. AHR is associated with the differentiation of Th subsets, particularly Th17 cells. The present study identified that no significant difference in AHR expression level was found between the PBMCs of the ND patients (median, 0.0148; range, 0.000131-0.0733), CR patients (median, 0.0184; range, 0.00167-0.0483) and controls (median, 0.0189; range, 0.00912-0.0380; Fig. 4C). In BMMCs, it was identified that AHR was markedly elevated in ND patients (median, 0.0129; range, 0.00025-0.0652) compared with CR patients (median, 0.0040; range, 0.00119-0.00989; $\mathrm{P}=0.013$; Fig. 4D).
Associations between NLRP3-related and Th-related molecules. The data indicated that there were positive correlations between NLRP3 inflammasome and Th subsets in BMMCs. In ND patients, it was identified that NLRP3 ( $\mathrm{r}=0.463, \mathrm{P}=0.003)$, caspase $-1 \quad(\mathrm{r}=0.7144, \mathrm{P}<0.001)$ or IL-1 $\beta(\mathrm{r}=0.571, \mathrm{P}<0.001)$ were positively correlated with AHR (Fig. 5A). In CR group, caspase-1 ( $\mathrm{r}=0.432, \mathrm{P}=0.031)$ and IL-1 $\beta(r=0.451, P=0.024)$ demonstrated positive correlation with AHR (Fig. 5B).

In PBMCs, it was identified that the expression levels of NLRP3 ( $\mathrm{r}=0.409, \mathrm{P}<0.001)$, ASC $(\mathrm{r}=0.319, \mathrm{P}=0.002)$, caspase-1 $(\mathrm{r}=0.568, \mathrm{P}<0.001), \mathrm{IL}-18(\mathrm{r}=0.415, \mathrm{P}<0.001)$ and IL-1 $\beta(r=0.465, \mathrm{P}<0.001)$ had positive correlations with the expression level of AHR in ND patients (Fig. 5C). In CR patients (Fig. 5D), it was also identified that the levels of inflammasome molecules and effector cytokines were positively correlated with AHR. In controls, it was observed that AHR was negatively correlated with caspase-1 ( $r=-0.425$, $\mathrm{P}=0.024$; Fig. 5E).

Correlation of NLRP3 inflammasome protein $m R N A$ levels with clinicopathological characteristics of patients with AML. Correlations between clinicopathological characteristics and NLRP3 inflammasome protein expression levels were investigated. The data indicated that IL-18 expression level was negatively correlated with the level of serum albumin $(r=-0.508$, 

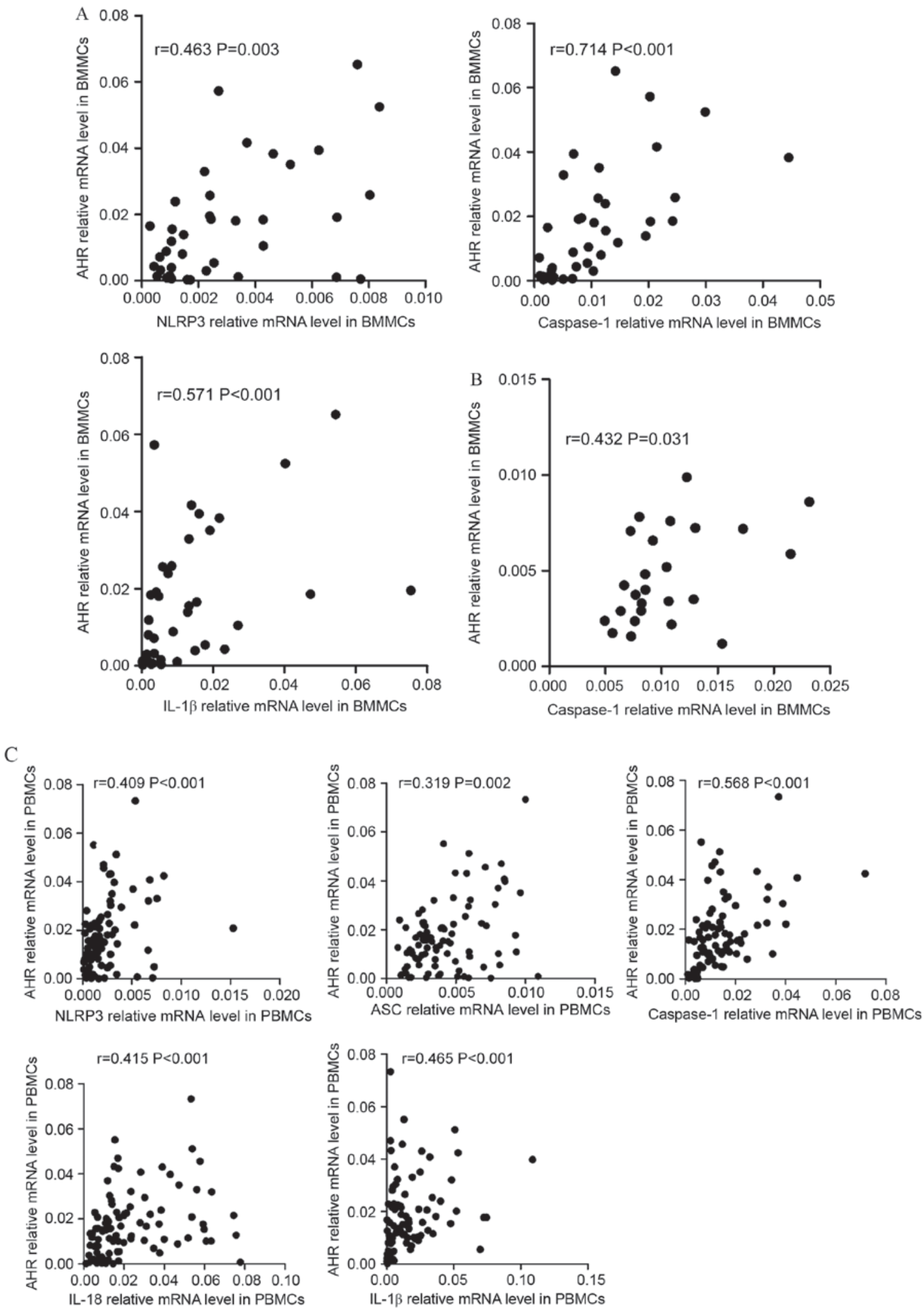

Figure 5. Correlations between NLRP3-related molecules and the Th-associated molecule AHR. (A) In the ND group, NLRP3, caspase-1 and IL-1 $\beta$ mRNA levels were positively correlated with AHR expression in the BM. (B) In CR patients, caspase-1 and IL-1 $\beta$ mRNA level were positively correlated with the relative level of AHR mRNA in the BM. (C) In ND patients, the expression of NLRP3, ASC, caspase-1, IL-18 and IL-1 $\beta$ mRNA were positively correlated with the relative AHR mRNA level in PBMCs. NLRP3, NLR family pyrin domain-containing 3; Th, T-helper cell; AHR, aryl hydrocarbon receptor; ND, newly diagnosed; IL, interleukin; CR, complete remission; ASC, apoptosis-associated speck-like protein; PBMCs, peripheral blood mononuclear cells.

$\mathrm{P}<0.001$; Fig. $6 \mathrm{~A})$ and positively correlated with lactate dehydrogenase ( $r=0.609, \mathrm{P}<0.001$; Fig. $6 \mathrm{~B})$ in all patients including
ND and CR patients. The association between NLRP3 inflammasome molecules and white blood cell (WBC) count in ND 


\section{$\mathrm{D}$}
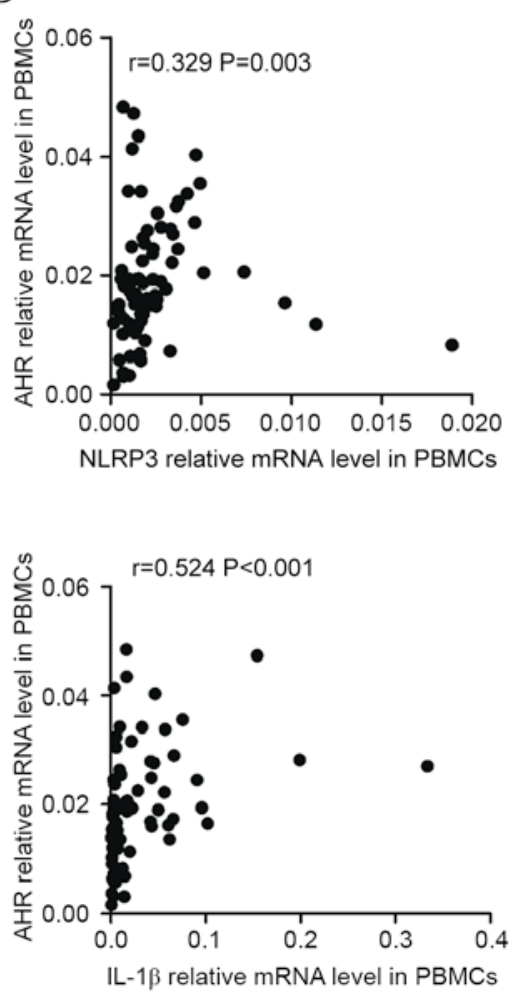
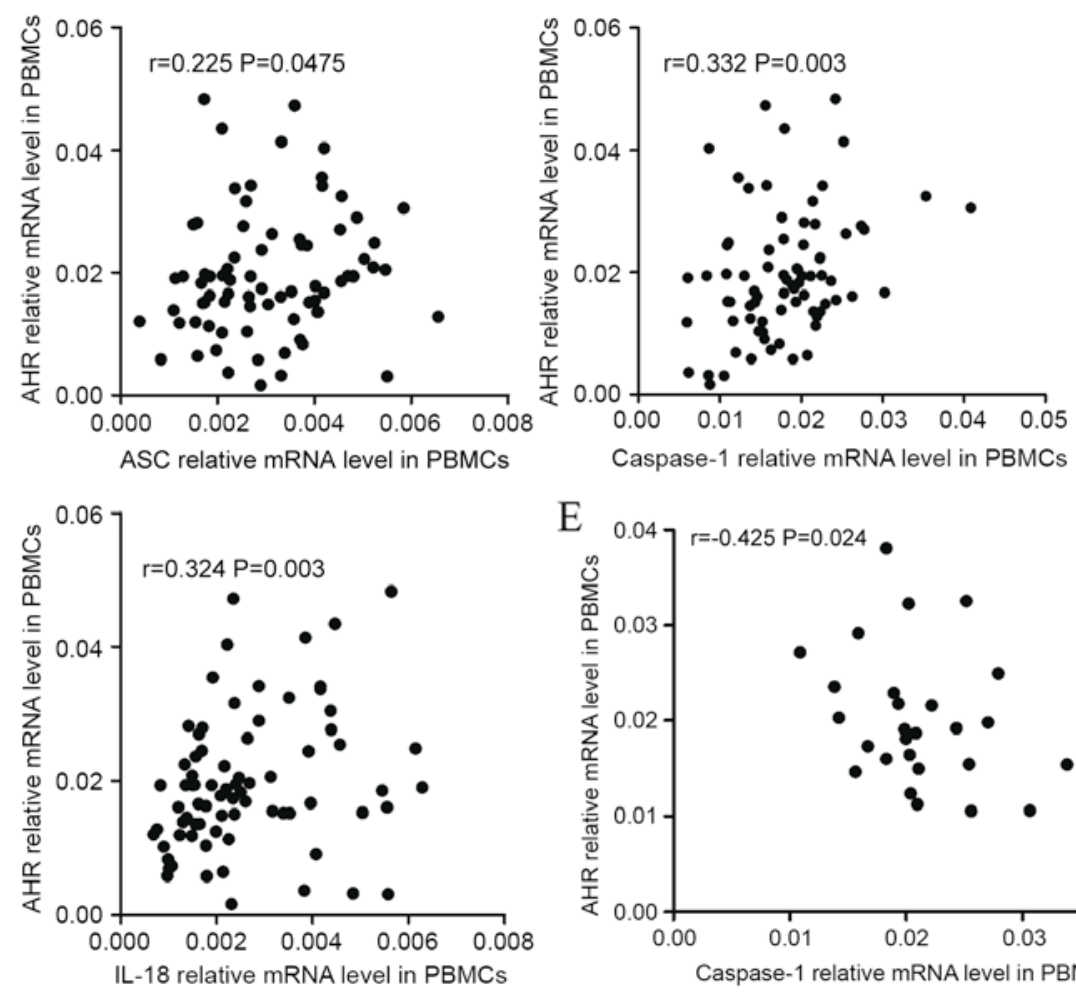

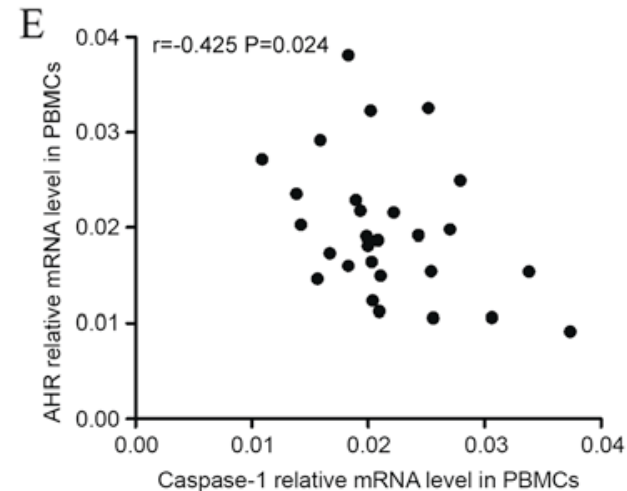

Figure 5. Continued. Correlations between NLRP3-related molecules and the Th-associated molecule AHR. (D) In PBMCs of the CR group, the levels of all NLRP3 inflammasome molecule and effector cytokine mRNA levels were positively correlated with the relative AHR mRNA level. (E) In the control group, the AHR level was observed to be negatively correlated with the caspase-1 mRNA level in PBMCs. NLRP3, NLR family pyrin domain-containing 3; Th, T-helper cell; AHR, aryl hydrocarbon receptor; ND, newly diagnosed; IL, interleukin; CR, complete remission; ASC, apoptosis-associated speck-like protein; PBMCs, peripheral blood mononuclear cells.

patients with AML was additionally assessed. Significant positive correlations between NLRP3 inflammasome molecule expression level (NLRP3, ASC, IL-1 $\beta$, and IL-18) and WBC count $(\mathrm{r}=0.296, \mathrm{P}=0.005 ; \mathrm{r}=0.219, \mathrm{P}=0.038 ; \mathrm{r}=0.321, \mathrm{P}=0.002$; $\mathrm{r}=0.358 \mathrm{P}=0.001$; respectively; Fig. $6 \mathrm{C}-\mathrm{F}$ ) were identified. AHR expression level was also positively correlated with WBC count in ND patients $(r=0.257, \mathrm{P}=0.015$; Fig. $6 \mathrm{G})$.

Chemotherapy recovered the aberrant expression of $I L-18$ and caspase-1 in the PBMCs of patients with AML. To further the understanding of the influence of chemotherapy on the immune system in AML, the complete treatment process of 28 patients with AML (PBMCs were obtained from 28/90 patients, including ND and CR patients) who obtained CR subsequent to standard induction chemotherapy was observed. It was identified that the expression of IL-18 in PBMCs was significantly decreased once the patients achieved $\mathrm{CR}(\mathrm{P}<0.001$; Fig. 7A). In the majority of ND patients (out of the 28 patients that PBMCs were obtained from), the expression of Caspase-1 was observed to be elevated after achieving $\mathrm{CR}(\mathrm{P}=0.004$; Fig. 7B).

\section{Discussion}

The importance of the immune system in AML is well recognized. Previous studies have suggested that Th1 and Th22 cells are involved in the development of AML $(1,2)$. Although the contribution of the NLRP3 inflammasome has been widely studied in many diseases, the specific role of the NLRP3 inflammasome in tumorigenesis is poorly understood. In the present study, it was demonstrated that the expression levels of NLRP3 molecules were significantly increased in BMMCs from ND patients compared with CR patients and that this was accompanied with elevated AHR. Aberrant levels of NLRP3 inflammasome molecules were also identified in PBMCs from ND patients. The results suggested that in patients with AML, the expression level of AHR was closely correlated with the expression of proteins from the NLRP3 inflammasome in BMMCs and PBMCs. Furthermore, abnormal proportions of Th subsets were identified in patients with AML, which was consistent with a previous study (1). Taken together, the data demonstrated that aberrant NLRP3 inflammasome and AHR expression were associated with the development of AML, and may contribute to the imbalance of Th subsets. The results indicated that an abnormal immune response was associated with the pathogenesis of AML.

The NLRP3 inflammasome is involved in autoimmune and inflammatory diseases, including ITP, multiple sclerosis, primary glomerular diseases and rheumatoid arthritis (RA) (22). The NLRP3 inflammasome was also previously demonstrated to serve an important role in metabolic diseases, including type II diabetes, gout and coronary artery disease (23). Currently, accumulating evidence indicates that the NLRP3 inflammasome is involved in the pathogenesis of tumors, the NLRP3 inflammasome correlated with the generation of tumor by regulating immune system; however, the 


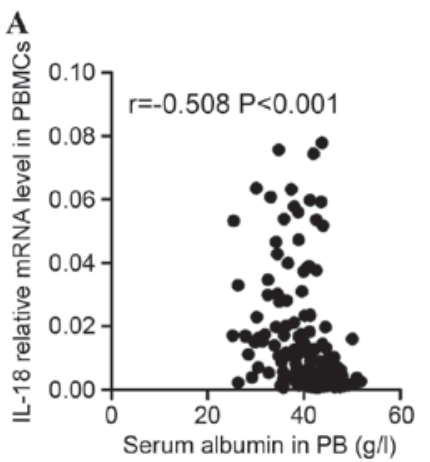

D
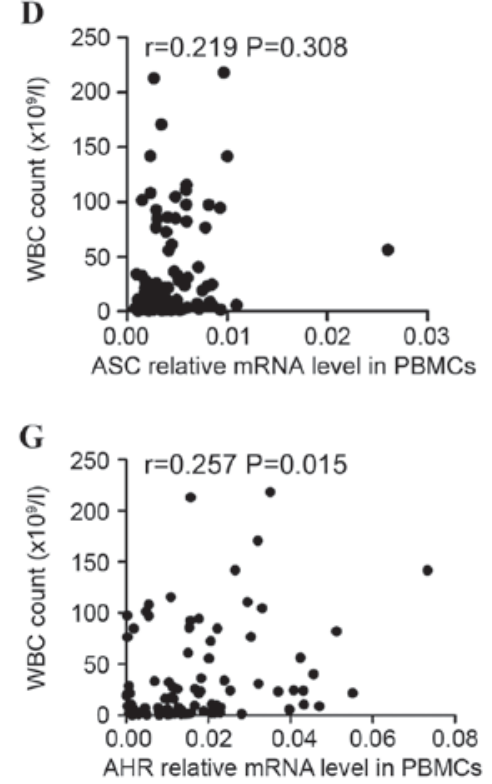

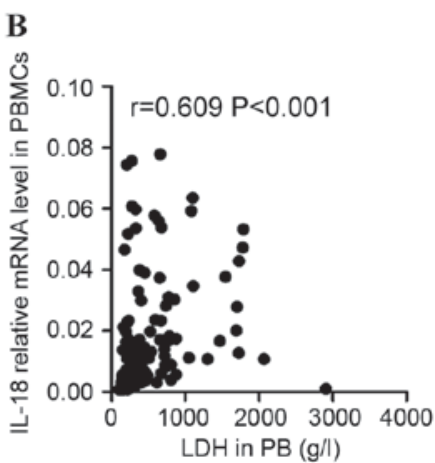

C

$\mathbf{E}$

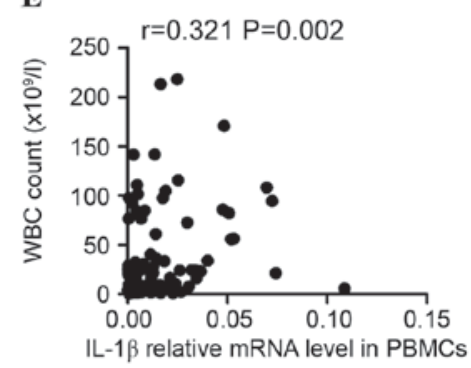

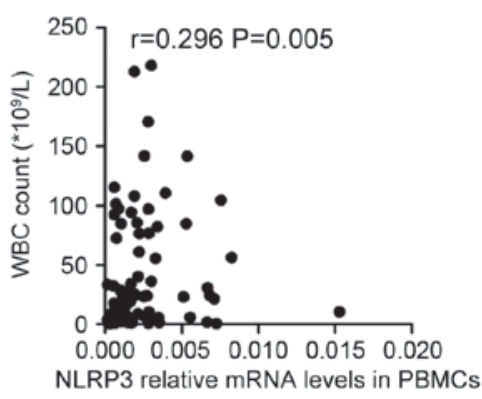

F

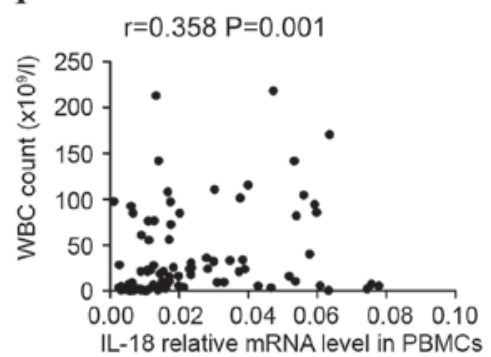

Figure 6. Correlations between the relative levels of NLRP3 inflammasome-associated molecules and clinical characteristics. The expression of IL-18 was (A) negatively correlated with the level of serum albumin and (B) positively correlated with the serum level of LDH in ND and CR patients. Significantly positive correlations between the relative mRNA levels of the NLRP3 inflammasome molecules [(C) NLRP3, (D) ASC, (E) IL-1 1 , (F) IL-18, (G) AHR] and WBC count were identified in the ND group. NLRP3, NLR family pyrin domain-containing 3; IL, interleukin; LDH, lactate dehydrogenase; ND, newly diagnosed; $\mathrm{CR}$, complete remission; ASC, apoptosis-associated speck-like protein; AHR, aryl hydrocarbon receptor; WBC, white blood cell.
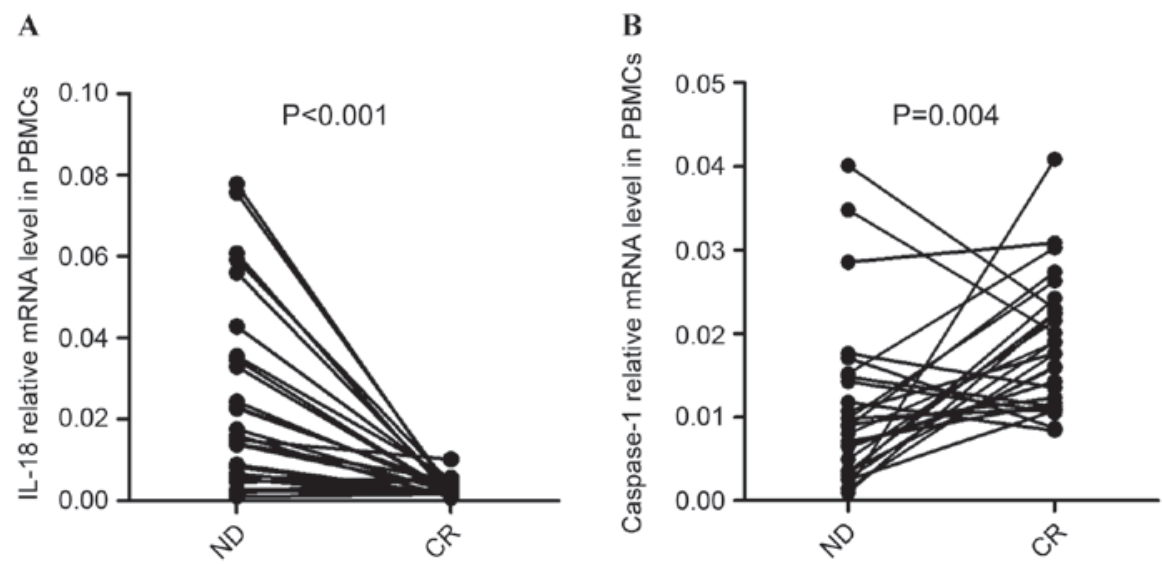

Figure 7. Differences in the mRNA expression level between patients at ND and following CR. (A) The expression of IL-18 mRNA in PBMCs was decreased significantly once patients achieved CR. (B) The relative level of caspase-1 mRNA was markedly increased once ND patients achieved CR. ND, newly diagnosed; CR, complete remission; IL, interleukin; PBMCs, peripheral blood mononuclear cells.

effect of the NLRP3 inflammasome and associated cytokines on tumor development remains unclear (24). Numerous studies showed that the NLRP3 inflammasome and its associated cytokines served a tumor-suppressive role in the development of cancer, whereas other findings have shown that NLRP3 inflammasome facilitated tumorigenesis $(25,26)$. In hepatocellular cancer (HCC), Wei et al demonstrated that patients with low expression levels of NLRP3 inflammasome components 
had a worse prognosis (27). Contradicting this, Terlizzi et al argued that patients with cancer with increased serum concentrations of IL-18 and IL-1 $\beta$ had a reduced disease-free survival time (28). The present study demonstrated that the NLRP3 inflammasome and associated cytokines were aberrantly expressed in ND patients with AML, which may be associated with the development of AML.

In the present study, the mRNA of the inflammasome molecules NLRP3, ASC and IL-18 was significantly increased in the BMMCs of ND patients compared with CR patients. Furthermore, in the ND group, the expression levels of NLRP3 inflammasome molecules were positively correlated with each other, whereas a decreased extent of correlation was identified in the CR group. These data suggest that the NLRP3 inflammasome plays a role in the pathology of AML in the BM microenvironment. In PBMCs, aberrant NLRP3 inflammasome protein expression levels were also identified in ND patients, but there was no significant difference in BMMCs. AML is a disease originating from the BM; the clinical symptoms of AML become apparent in the BM first, and after a period of time, are demonstrated in the peripheral blood (14). This may explain the difference between the results for BMMCs and PBMCs.

The result in PBMCs suggested that the expression of the NLRP3 inflammasome molecules NLRP3, ASC and caspase-1 were positively correlated with each other in ND and CR patients, whereas in controls, only a positive correlation between NLRP3 and ASC was identified. Additionally, the expression levels of the effective cytokines IL-1 $\beta$ and IL-18 were observed to be positively correlated with the levels of NLRP3 inflammasome molecules in ND and CR patients with AML. However, in controls, no correlation between NLRP3 inflammasome molecules and the effective cytokines was identified.

AHR has been hypothesized to negatively regulate the NLRP3 inflammasome by inhibiting the transcription of NLRP3 (17). The results of the present study suggested that the relative AHR expression level differed between BMMCs and PBMCs. In BMMCs, AHR was found to be markedly elevated in ND patients when compared with CR patients. Furthermore, the AHR expression level was positively correlated with the level of NLRP3 inflammasome molecules in the BMMCs and PBMCs of patients with AML. A balance must be maintained between the activation and inhibition of the inflammasome to avoid detrimental effects (17). The abnormally elevated expression of AHR and NLRP3 may contribute to the pathogenesis of AML.

AHR serves a critical role in the regulation of the immune response, including in the innate and adaptive immune responses (16). Emerging evidence suggests that AHR expression level is correlated with the differentiation of $\mathrm{Th}$ subsets (29). Negishi et al demonstrated that AHR participated in the modulation of the Th1/Th2 balance in vivo (30). Accumulating reports have also demonstrated that AHR serves a pivotal role in the development of autoimmune disorders, including inflammatory bowel diseases, RA and systemic lupus erythematosus by impairing the balance of Th1, Th17 and regulatory $\mathrm{T}$ cells (Tregs) (31-33). Moreover, emerging studies have demonstrated that the activation of AHR aberrantly induced Th17/Tregs though prompting the generation of Tregs and suppressing Th17 cells (34). Quintana et al (35) demonstrated that AHR modulated the differentiation of Tregs and Th17 in a ligand-specific manner. AHR activation by its ligand, 2,3,7,8-tetrachlorodibenzo-p-dioxin, induces functional T(reg) cells, however, AHR activation by 6 -formylindolo [3,2-b] carbazole promotes $\mathrm{T}(\mathrm{H}) 17$ cell differentiation and accelerates the severity of experimental autoimmune encephalomyelitis in animal experiments (35). The result of the present study revealed that AHR expression in BMMCs from ND patients with AML was markedly increased compared with CR patients.

Previous studies have demonstrated that imbalanced Th subsets were involved in the pathologies of hematological malignancies $(1,14)$. The present study has identified that Th22 in PB was markedly increased in ND patients compared with CR patients or controls. The frequency of Th1 cells was also reduced in ND patients. Therefore, we hypothesize that the expression of AHR in patients with AML may result in the aberrant Th subsets.

Tregs serve a key role in the maintenance of immune homeostasis and are elevated in tumors $(36,37)$. In a previous study, Tregs were observed to be at an increased level in an ND group compared with a CR group although the mechanism was unclear (2). In a mouse model, it was identified that DC-derived IL-18 promoted the differentiation of $\mathrm{T}$ cells towards CD4+CD25+ Tregs (38). The result of the present study demonstrated that IL-18 was increased in ND patients with AML, which may facilitate the polarization of Tregs. Tregs in patients with AML may have suppressed the immune response and promoted the development of AML.

A recent study associated the NLRP3 inflammasome with Th differentiation. Peelen et al identified that inflammasome activity promoted naive CD4+ T-cell differentiation into pro-inflammatory subsets, particularly Th17 (39). Th22 is a newly identified Th subset that is associated not only with the immune response, but also inflammation. It was recently demonstrated that Th22 may also be involved in the pathogenesis of a number of tumor types, including HCC (40) and cervical cancer (41). In the present study, it was identified that the relative proportion of Th22 was significantly higher in ND patients than in CR patients and controls. Furthermore, AHR expression level was positively correlated with NLRP3 inflammasome molecule expression level, and the associated cytokines IL-1 $\beta$ and IL-18, in patients with AML. The results suggest that aberrant NLRP3 inflammasome protein and AHR expression may influence the differentiation of $\mathrm{Th}$ subsets in the development of AML.

In conclusion, the results of the present study suggested that the NLRP3 inflammasome, which was associated with AHR, played a role in the pathogenesis of AML, contributing to the imbalance of Th subset proportion. Based on this observation, targeting the NLRP3 inflammasome may be considered as a novel potential treatment option against AML. Further studies are awaited in order to clarify the specific role and mechanism of the NLRP3 inflammasome in the immunopathology of AML.

\section{Acknowledgements}

The present study was supported by grants from the National Natural Science Foundation of China (grant no. 81470319) and 
the Natural Science Foundation of Shandong Province (grant no. ZR2015PH060).

\section{References}

1. Yu S, Liu C, Zhang L, Shan B, Tian T, Hu Y, Shao L, Sun Y, Ji C and Ma D: Elevated Th22 cells correlated with Th17 cells in peripheral blood of patients with acute myeloid leukemia. Int J Mol Sci 15: 1927-1945, 2014.

2. Lucas CM, Wang L, Austin GM, Knight K, Watmough SJ, Shwe KH, Dasgupta R, Butt NM, Galvani D, Hoyle CF, et al: A population study of imatinib in chronic myeloid leukaemia demonstrates lower efficacy than in clinical trials. Leukemia 22 1963-1966, 2008.

3. Neill DR, Wong SH, Bellosi A, Flynn RJ, Daly M, Langford TK, Bucks C, Kane CM, Fallon PG, Pannell R, et al: Nuocytes represent a new innate effector leukocyte that mediates type-2 immunity. Nature 464: 1367-1370, 2010.

4. Shao BZ, Xu ZQ, Han BZ, Su DF and Liu C: NLRP3 inflammasome and its inhibitors: A review. Front Pharmacol 6: 262, 2015.

5. Sutterwala FS, Haasken S and Cassel SL: Mechanism of NLRP3 inflammasome activation. Ann NY Acad Sci 1319: 82-95, 2014.

6. Bauernfeind FG, Horvath G, Stutz A, Alnemri ES, MacDonald K, Speert D, Fernandes-Alnemri T, Wu J, Monks BG, Fitzgerald KA, et al: Cutting edge: NF-kappaB activating pattern recognition and cytokine receptors license NLRP3 inflammasome activation by regulating NLRP3 expression. J Immunol 183: 787-791, 2009.

7. Ozaki E, Campbell M and Doyle SL: Targeting the NLRP3 inflammasome in chronic inflammatory diseases: Current perspectives. J Inflamm Res 8: 15-27, 2015.

8. Zhang N, Pan HF and Ye DQ: Th22 in inflammatory and autoimmune disease: Prospects for therapeutic intervention. Mol Cell Biochem 353: 41-46, 2011.

9. Cheng F, Guo Z, Xu H, Yan D and Li Q: Decreased plasma IL22 levels, but not increased IL17 and IL23 levels, correlate with disease activity in patients with systemic lupus erythematosus. Ann Rheum Dis 68: 604-606, 2009.

10. Nickoloff BJ: Cracking the cytokine code in psoriasis. Nat Med 13: 242-244, 2007.

11. Brand S, Beigel F, Olszak T, Zitzmann K, Eichhorst ST, Otte JM Diepolder H, Marquardt A, Jagla W, Popp A, et al: IL-22 is increased in active Crohn's disease and promotes proinflammatory gene expression and intestinal epithelial cell migration. Am J Physiol Gastrointest Liver Physiol 290: G827-G838, 2006.

12. Shao LL, Zhang L, Hou Y, Yu S, Liu XG, Huang XY, Sun YX, Tian T, He N, Ma DX, et al: Th22 cells as well as Th17 cells expand differentially in patients with early-stage and late-stage myelodysplastic syndrome. PLoS One 7: e51339, 2012.

13. Hu Y, Li H, Zhang L, Shan B, Xu X, Li H, Liu X, Xu S, Yu S Ma D, et al: Elevated profiles of Th22 cells and correlations with Th17 cells in patients with immune thrombocytopenia. Hum Immunol 73: 629-635, 2012.

14. Tian T, Sun Y, Li M, He N, Yuan C, Yu S, Wang M, Ji C and Ma D: Increased Th22 cells as well as Th17 cells in patients with adult T-cell acute lymphoblastic leukemia. Clin Chim Acta 426 108-113, 2013

15. Goergens A, Frericks M and Esser C: The arylhydrocarbon receptor is only marginally involved in the antileukemic effects of its ligand curcumin. Anticancer Res 29: 4657-4664, 2009

16. Zhu C, Xie Q and Zhao B: The role of AhR in autoimmune regulation and its potential as a therapeutic target against CD4 T cell mediated inflammatory disorder. Int J Mol Sci 15: 10116-10135, 2014.

17. Huai W, Zhao R, Song H, Zhao J, Zhang L, Zhang L, Gao C, Han L and Zhao W: Aryl hydrocarbon receptor negatively regulates NLRP3 inflammasome activity by inhibiting NLRP3 transcription. Nat Commun 5: 4738, 2014.

18. Gris D, Ye Z, Iocca HA, Wen H, Craven RR, Gris P, Huang M, Schneider M, Miller SD and Ting JP: NLRP3 plays a critical role in the development of experimental autoimmune encephalomyelitis by mediating Th1 and Th17 responses. J Immunol 185 : 974-981, 2010.

19. Cheson BD, Cassileth PA, Head DR, Schiffer CA, Bennett JM, Bloomfield CD, Brunning R, Gale RP, Grever MR, Keating MJ, et al: Report of the national cancer institute-sponsored workshop on definitions of diagnosis and response in acute myeloid leukemia. J Clin Oncol 8: 813-819, 1990.
20. Vardiman JW: The Word Health Organization (WHO) classification of tumors of the hematopoietic and lymphoid tissues: An overview with emphasis on the myeloid neoplasms. Chem Biol Interact 184: 16-20, 2010

21. Livak KJ and Schmittgen TD: Analysis of relative gene expression data using real-time quantitative PCR and the 2(-Delta Delta $\mathrm{C}(\mathrm{T})$ ) method. Methods 25: 402-408, 2001.

22. Mathews RJ, Robinson JI, Battellino M, Wong C, Taylor JC; Biologics in Rheumatoid Arthritis Genetics and Genomics Study Syndicate (BR AGGSS), Eyre S, Churchman SM, Wilson AG, Isaacs JD, et al: Evidence of NLRP3-inflammasome activation in rheumatoid arthritis (RA); genetic variants within the NLRP3-inflammasome complex in relation to susceptibility to RA and response to anti-TNF treatment. Ann Rheum Dis 73 1202-1210, 2014

23. Satoh M, Tabuchi T, Itoh T and Nakamura M: NLRP3 inflammasome activation in coronary artery disease: Results from prospective and randomized study of treatment with atorvastatin or rosuvastatin. Clin Sci (Lond) 126: 233-241, 2014.

24. Karki R, Man SM and Kanneganti TD: Inflammasomes and cancer. Cancer Immunol Res 5: 94-99, 2017.

25. Terlizzi M, Colarusso C, Popolo A, Pinto A and Sorrentino R: IL-1 $\alpha$ and IL-1 $\beta$ producing macrophages populate lung tumor lesions in mice. Oncotarget 7: 58181-58192, 2016.

26. Petrilli V: The multifaceted roles of inflammasome proteins in cancer. Curr Opin Oncol 29: 35-40, 2017.

27. Wei Q, Mu K, Li T, Zhang Y, Yang Z, Jia X, Zhao W, Huai W, Guo P and Han L: Deregulation of the NLRP3 inflammasome in hepatic parenchymal cells during liver cancer progression. Lab Invest 94: 52-62, 2014

28. Terlizzi M, Casolaro V,Pinto A and Sorrentino R: Inflammasome: Cancer's friend or foe? Pharmacol Ther 143: 24-33, 2014.

29. Busbee PB, Rouse M, Nagarkatti M and Nagarkatti PS: Use of natural AhR ligands as potential therapeutic modalities against inflammatory disorders. Nutr Rev 71: 353-369, 2013.

30. Negishi T, Kato Y, Ooneda O, Mimura J, Takada T, Mochizuki H, Yamamoto M, Fujii-Kuriyama Y and Furusako S: Effects of aryl hydrocarbon receptor signaling on the modulation of TH1/TH2 balance. J Immunol 175: 7348-7356, 2005

31. Arsenescu R, Arsenescu V, Zhong J, Nasser M, Melinte R, Dingle RW, Swanson H and de Villiers WJ: Role of the xenobiotic receptor in inflammatory bowel disease. Inflamm Bowel Dis 17: 1149-1162, 2011.

32. Kobayashi S, Okamoto H, Iwamoto T, Toyama Y, Tomatsu T, Yamanaka $\mathrm{H}$ and Momohara S: A role for the aryl hydrocarbon receptor and the dioxin TCDD in rheumatoid arthritis. Rheumatology (Oxford) 47: 1317-1322, 2008

33. Yang J, Yang X, Zou H, Chu Y and Li M: Recovery of the immune balance between Th17 and regulatory T cells as a treatment for systemic lupus erythematosus. Rheumatology (Oxford) 50: 1366-1372, 2011.

34. Hanieh H: Toward understanding the role of aryl hydrocarbon receptor in the immune system: Current progress and future trends. Biomed Res Int 2014: 520763, 2014.

35. Quintana FJ, Basso AS, Iglesias AH, Korn T, Farez MF, Bettelli E, Caccamo M, Oukka M and Weiner HL: Control of $\mathrm{T}(\mathrm{reg})$ and $\mathrm{T}(\mathrm{H}) 17$ cell differentiation by the aryl hydrocarbon receptor. Nature 453: 65-71, 2008.

36. Wing JB and Sakaguchi S: Foxp3 ${ }^{+} \mathrm{T}(\mathrm{reg})$ cells in humoral immunity. Int Immunol 26: 61-69, 2014.

37. Nishikawa $\mathrm{H}$ and Sakaguchi S: Regulatory $\mathrm{T}$ cells in cancer immunotherapy. Curr Opin Immunol 27: 1-7, 2014.

38. Oertli M, Sundquist M, Hitzler I, Engler DB, Arnold IC, Reuter S, Maxeiner J, Hansson M, Taube C, Quiding-Järbrink M and Müller A: DC-derived IL-18 drives Treg differentiation, murine Helicobacter pylori-specific immune tolerance, and asthma protection. J Clin Invest 122: 1082-1096, 2012.

39. Peelen E, Damoiseaux J, Muris AH, Knippenberg S, Smolders J, Hupperts R and Thewissen M: Increased inflammasome related gene expression profile in PBMC may facilitate T helper 17 cell induction in multiple sclerosis. Mol Immunol 63: 521-529, 2015.

40. Qin S, Ma S, Huang X, Lu D, Zhou Y and Jiang H: Th22 cells are associated with hepatocellular carcinoma development and progression. Chin J Cancer Res 26: 135-141, 2014.

41. Zhang W, Tian X, Mumtahana F, Jiao J, Zhang T, Croce KD, Ma D, Kong B and Cui B: The existence of Th22, pure Th17 and Th1 cells in CIN and cervical cancer along with their frequency variation in different stages of cervical cancer. BMC Cancer 15: 717, 2015. 